\title{
Analytical Study of Pancreatitis in Dogs
}

\author{
Rahmoun Djallal Eddine* and Fares Mohamed Amine \\ Institute of Agronomic and Veterinary Sciences of Taoura, Algeria
}

Submission: March 03, 2018; Published: May 16, 2018

*Corresponding author: Rahmoun Djallal Eddine, Institute of Agronomic and Veterinary Sciences of Taoura - Souk Ahras, Algeria,

Tel: +213663121367; Email: Deddine44@hotamail.com

\begin{abstract}
A number of theoretical and practical questions about canine pancreatitis persuading that anatomical and morphological changes, also biochemical, are the only diagnostic mode for this disease that affects the pancreas, major roles in the digestion and secretion of endocrine hormones. Analysis of literature data on biochemical parameters during pancreas functions exam; a diagnosis performed on serum enzyme correlations changes during pancreatitis treatment in experimental animals determined by statistical analysis of biochemical parameters of canine pancreatitis. The demonstration of typical clinical signs of this disease adjusted by the typical methods of diagnosis, will develop the topical treatment can be established and treatments.
\end{abstract}

Keywords: Canine pancreatitis; Diagnostic; Biochemical parameters; Serum; Enzyme; Statistical analysis; Sedimentation rate; Necrosis; Hemorrhagic; Epigastric; Palpation; Relapses; Hyper-secretion; ; Bilirubin; Glucoseurea; Creatinine

Abbreviations: ALT: Alanine Amino-Transferase; AST: Aspartate Amino-Transferase; ESR: Erythrocyte Sedimentation Rate

\section{Introduction}

Severity of pancreas symptoms changes could be benign (edematous pancreatitis) or severe and even life menacing (pancreatic necrosis hemorrhagic). A variety of clinical manifestations associated with metabolic disorders and secretion of toxic enzymes and involved in process of gastrointestinal tract, liver and reins [1]. This usually complicates the clinical diagnosis. Acute pancreatitis in canine can occur following clinical signs: anorexia, vomiting, mild diarrhea, bowel obstruction, epigastric dolor during palpation, abdominal wall tension, mild swelling of the abdomen, fever, tachypnea, dehydration, depression, oliguria, often with presence of white foamy liquid, strong salivation and bradycardia, hypovolemic circulatory shock, depression due to hypo-calcemia, Chronic pancreatitis in the canine can manifest repeatedly, inflammatory or implicit progressive interstitial pancreatitis [2]. Canines are the most common of recurring, leading to occasional digestive problems such as vomiting and diarrhea. Dolor during abdominal wall palpation and other severe symptoms are rare in intervals between individual attacks (relapses) behave as healthy dogs, Animals receiving "worshipers" position: Member stretched forward, the chest resting on the ground and the posterior of the body is raised. Dolor accompanied by vomiting. Exhaustion rarely occurs due to parenchyma progressive destruction and its replacement by fibrosis or cirrhosis of the connective tissue [3].

Chronic pancreatitis is accompanied by dolor, dyspeptic and cholestatic syndrome, jaundice symptoms, exocrine pancreatic insufficiency with progressive weight loss. Other symptoms are observed in the liver [4], bile ducts, intestines and kidneys [5]. Chronic pancreatitis characterized by deficiency of following characteristics of pancreatic cancer: diarrhea, steatorrhea, intestinal bloating, enterocolitis. Mortality of the animal clearly decreases [6]. During acute pancreatitis amylase in serum increased by more than $60 \mathrm{~g} / \mathrm{L}$, Lipase - to $110-200 \mathrm{U} / \mathrm{ml}$. Slight change in enzyme activity in chronic pancreatitis; increase of serum gamma-globulin, lymphocytes sensitized by action of auto-antibodies against pancreatic antigens. In the presence of pancreatic lithiasis that lead to constipation, dolor in the large intestine due to irritation of the nerve roots implanted in the placement area of the pancreas. This increases the activity of amylase in the blood [7]. The screening of pancreatitis in animals is difficult enough. Among the diagnostic methods: radio diagnosis, ultrasound [8] and biopsy [9].

\section{Objectives}

Determination of clinical and diagnostic value of enzyme hyper-secretion of canine pancreatitis, Summarize the data obtained. Build data in a table and hold their statistical processing.

\section{Clinical Research Methods}

Seventy dogs with pancreatitis were assigned for our twoyear period search, observed clinical outcome such as, body temperature, respiratory and cardiac frequency, palpation, 
percussion, auscultation of heart and lungs and abdominal cavity, special research methods are bilirubin, glucose, urea, creatinine; ALT (alanine amino-transferase), AST (Aspartate aminotransferase) activity and amylase, alpha-amylase, which increases 3 or more times in acute form; less information is inherent to the activity of ALT and AST, recommended in the diagnosis of canine pancreatitis. Alsohemoglobin, ESR (Erythrocyte sedimentation rate),number of erythrocytes, leukocytes, segmented nuclei, and pulmonary leukocytes, lymphocytes, myelocyte, monocytes, eosinophils and basophils, in the end we used the ultrasound examination of abdominal cavity organs.

\section{Results}

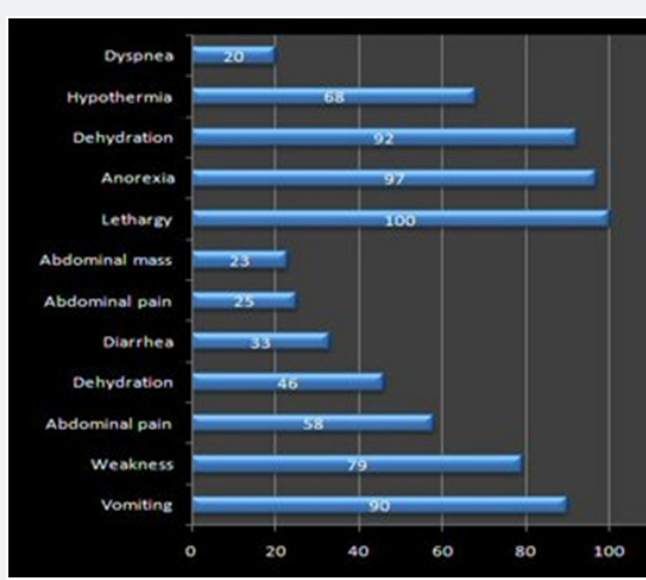

Figure 1: Diagram of the variations of the symptoms of pancreatitis in 70 dogs.

After summarizing clinical examination data, animals that were suspected of having a disease with pancreatitis were found to have common and frequently manifested clinical symptoms. The clinical signs vary and depend on the severity of pancreatitis. The mild cases may be asymptomatic. According to the clinical signs encountered (studies on 70 dogs with pancreatitis): Anxiety, looking at the epigastric site, hyper salivation, vomiting with white foam, abdominal pain on the pancreas site; pancreas during palpation and tension of the abdominal wall, the analgesic position, sometimes there was an icterous mucous membrane, The symptoms found are quoted in the following diagram
(Figure 1), show a multitude variation: The first symptoms of pancreatitis in dogs observed are refusal of food and weakness. Signs of anxiety and vomiting. This is typical of pancreatitis. In addition, the symptomatology is as follows: the palpation of the abdominal wall of the dogs in the region of the pancreas is very painful, bloating is observed. Diarrhea or constipation. Feces are very dense or with mucus. There may be intestinal obstruction or peritonitis has been seen. Since the period of illness, the animal has vomiting and diarrhea, dehydration is taking place. A disturbance of cardiac activity and respiration, as hyperthermia. In severe cases, there is a shock. With the diagnosis of pancreatitis in dogs, a higher level of lipase and amylase in the blood during pancreatitis (Figure 1).

It was the mostcomplete, to eliminate the causes of the disease, removing the main syndromes accompanying pancreatitis, to alleviate the condition of the animals, standardizing the work of affected organs and systems, recovery and normalization the digestion. Thus, a strict diet was prescribed, anti-allergic, antiemetic drug to eliminate pain. Histopathological result makes an image with the progressive destruction of the parenchyma and its replacement by fibrosis or cirrhosis of the connective tissue (Figure 2).

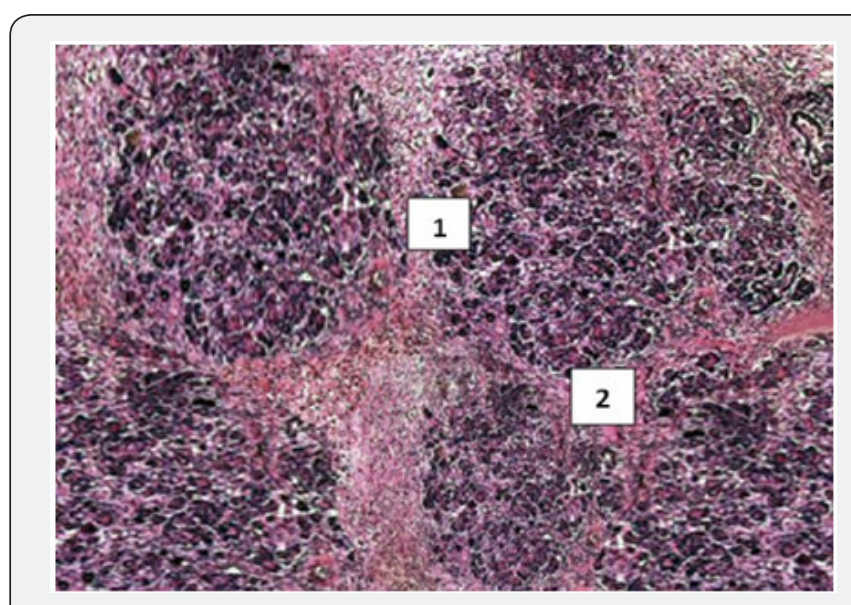

Figure 2: Pancreatitis, pancreatic parenchyma with necrosis deposit in

1. Peri-lobular tissue and cellular 2. Fibrosis in the surrounding zone.

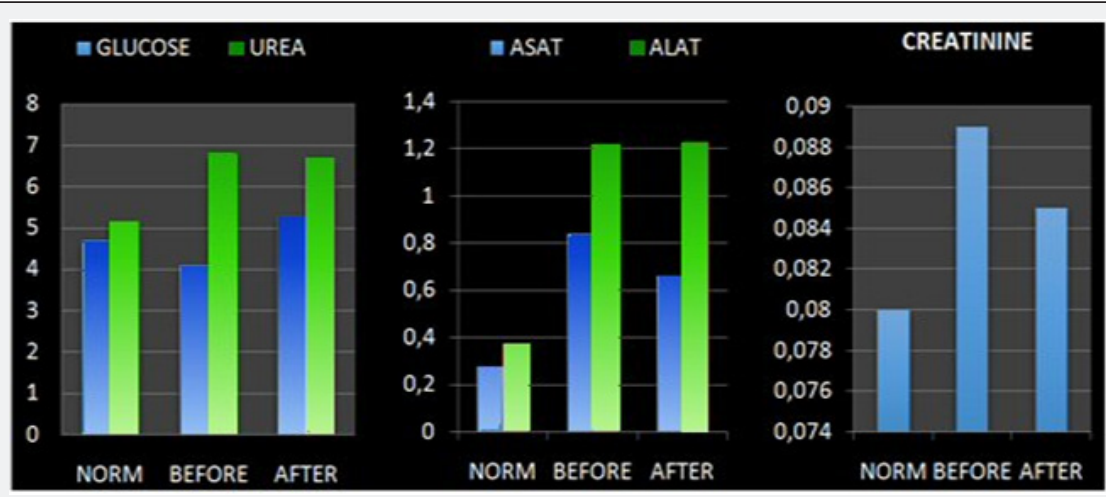

Figure 3: Dynamic of biochemical analyzes $(\mathrm{mmol} / \mathrm{l})$ of canine blood pancreatitis before and after treatment. 
For all histological features, dogs were categorized as having no histological evidence of pancreatitis, pancreatic fatty necrosis and edema were observed, 14 dogs were classified as having no evidence of pancreatitis. Lipase concentration was within the reference range in 21 dogs and was below the cut off for the diagnosis of pancreatitis ( $400 \mu \mathrm{g} / \mathrm{L}$ ) (Figure 3).

Exploration with ultrasound of acute canine pancreatitis; enlarged pancreas in irregular and hypoechoic shape, with reduction of maximum width in relation to its length; in contrast for chronic pancreatitis; the size of the pancreas has decreased (Figure 4). Pancreatitis diagnosis is challenge, because of clinical signs associated the condition can be vague and vary widely between individuals, based on human medicine, acute pancreatitis can be defined as a completely reversible condition when the primary cause is removed, while chronic pancreatitis is characterized by irreversible histopathological changes (atrophy or fibrosis). Both forms of pancreatitis may be mild or severe (pancreatic necrosis, involvement of several organs) (Figure 4).

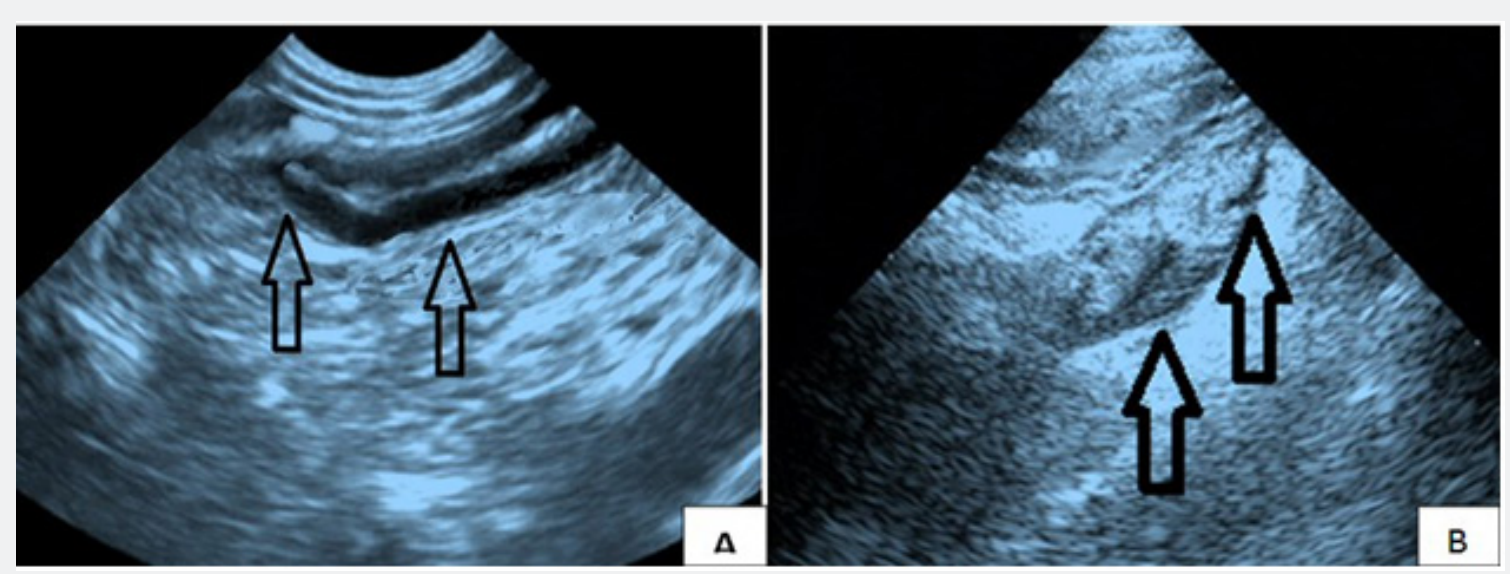

Figure 4: Ultrasound examination:

A. Regular normal dog pancreas, contour and no visible nodules.

B. Pancreatitis of a dog, appear as hypo echoic nodules. $2.5 \mathrm{~cm}$, changes thickening of the pancreas.

\section{Conclusion}

Dogs can suffer from pancreatitis (inflammation of the pancreas) that can be acute or chronic. The diagnosis of pancreatitis is difficult; it is based on the confrontation between the symptoms presented by the animal and the results of various complementary examinations. The symptoms vary between acute form and chronic form. The treatments put in place are also different during acute and chronic pancreatitis.

\section{Limitations}

The main limitation of this study is the lack of publication and work in this area of research, which allows us to not make a scientific comparison to get more results.

\section{Recommendations}

The researchers recommend the continuation of their studies on a multidisciplinary study on the histology, biochemistry, to allow having a a significant range in the diagnosis of pancreatitis, ultrasound also allows the monitoring of the state of the animal, To conduct educational activities on the dangers of pancreatitis in animals and provide advice on the prevention of this pathology, data obtained in the veterinary setting of this work may be recommended for early diagnosis and improvement of canine pancreatic diseases.

\section{References}

1. Anderson R, Wang X, I Ihse (1972) the influence of abdominal sepsis on acute pancreatitis in rats. a study on mortality, permeability, arterial pressure and intestinal blood flow. Pancreas 11(4): 365-373.

2. Trehy MR, Batchelor D, Noble PK (2013) Serum pancreas specific lipase concentrations in dogs with upper gastrointestinal foreign bodies. J Vet Intern Med 28: 711-744.

3. Zheng Huichang, Liu Jiwu, Pan Dong, TongzeJi, Xiong Xilong, et al. (1995) The morphology of the pancreas lobes abducts of the wild duckAythyaferina in China. II Acta Agr Univ Pekin 21: 104-110.

4. Kelli EJ (1993) Immunocytochemical localization of pariental cells and G cells within the developing human stomach. Gut 34(8): 1057-1059.

5. De Ritis F, Coltorti M, Guisti G (1972) Serum transaminase activities in liver disease. Lancet, pp. 685.

6. Konde LJ (1999) Renal sonography. Seminars in Veterinary Medicine and Surgery (small animal) p. 4.

7. Kaplan PM, Murtaugh RJ, Ross JN (1988) Ultrasound in Emergency. Veterinary Medicine and Surgery Seminars (Small Animals) 3: 245254.

8. McKenzie R, Fred MW, Sallic R et al (1995) Hepatic failure air a lactic acidosis due to fialuridine (FIAU), as investigational nucleoside analogue for chronic hepatitis BN Engl J Med, pp. 333-1099.

9. Simpson RW, Neiger R, DeNovo R, Sherding R (2000) The relationship of Helicobacter spp. Infection to gastric disease in dog and. Journal of Veterinary Internal Medicine 14: 223-227. 
(C) This work is licensed under Creative (C) Commons Attribution 4.0 License DOI: 10.19080/JDVS.2018.06.555681

\section{Your next submission with Juniper Publishers} will reach you the below assets

- Quality Editorial service

- Swift Peer Review

- Reprints availability

- E-prints Service

- Manuscript Podcast for convenient understanding

- Global attainment for your research

- Manuscript accessibility in different formats ( Pdf, E-pub, Full Text, Audio)

- Unceasing customer service

Track the below URL for one-step submission https://juniperpublishers.com/online-submission.php 